\title{
Use of webcasting and development of critical thinking skills
}

\author{
Antonella Poce; Francesco Agrusti and Maria Rosaria Re
}

Department of Education, Roma Tre University, Italy.

\begin{abstract}
The present contribution describes the results of a research carried out at the Laboratory of Experimental Research - Department of Education, Roma TRE University. Main aim of the research is to assess if it possible to increase critical thinking skills in university students, through meaningful online cultural insights in general and webcasting in particular. Students in Education attended part of the course "Methodology of Research" online, through a webcasting activity: cultural insights, guided discussions, videos, built on structured models, prompted reasoning, elaboration of ideas and knowledge connections. Students had the possibility to deepen knowledge and abilities linked to the themes of the course, but also to develop argumentation skill, communication and critical evaluation skill. The data analysis presented in this report were developed along the double diachronic and synchronic dimensions; the evolution of critical thinking skills has been verified by the lexicon-metric analyses of written production.
\end{abstract}

Keywords: Webcasting; Critical thinking skills; Assessment. 


\section{State of the $\operatorname{art}^{1}$}

The crisis which has been affecting the Western world during the last decades, indeed, force to the adoption of different solutions, especially in the field of Higher Education. The situation makes the realization of innovation necessary, but such innovation should support the development of new competences and skills, as reminded by the European Commission (Rethinking Education, 2012). The aim of integrating digital resources and opportunities in education has to be seen in the light of 21 st century learning: in their work titled "21st Century Skills: Learning for Life in Our Times" (2009), Trilling \& Fadel create a framework of cross-sectional skills necessary to prepare society for the complex 21 st century reality : critical thinking, creativity, communication and collaboration (the $4 \mathrm{C}$ 's) are considered as pivotal for realization and personal development, active citizenship, social inclusion and employment.

The development of such kind of abilities and skills cannot be solved with interventions based on the mere employment of technology. The culture of technology lacks depth, being characterized by the speed at which the various technical solutions follow each other on the market. It is necessary to find a coherent and effective system of connection between the promotion of skills in a lifelong learning prospective and the transitory function of technological tools (Vertecchi, 2012).

One of the main problem we are facing at the moment is that of a general lack of researches in the field of webcasting use in Higher Education and transversal skills promotion. As Traphagan et al. states (2009), webcasts or podcasts are mostly used in higher education as broadcasting lectures, delivering recordings of in-class lectures, guest lecturers and as supplementary video learning materials for self-study. Some studies have underlined that webcasting and podcasting use in higher education can develop cognitive understanding through motivation and engagement (Oliver, 2005) and information processing (Hargis and Wilson, 2005), but only a limited amount of research highlights the connection between students' transversal skills promotion and webcasting use; therefore, part of them refers only to student attitude and student behaviour (Kurtz et al., 2007; Giannakos and Vlamos, 2013).

The purpose of the present study is to demonstrate that technology in general and webcasting in particular, if used adopting criteria based on a structured reference model, are able to provide a stable architecture for further study and to promote the construction of a responsible and critical conscience in the young generation. As Poce states (2012) "the

\footnotetext{
1 A. Poce coordinated the research presented in this paper. Research group is composed by the authors of the contribution that was edited in the following order: A. Poce (State of the art, Research Hypothesis and objectives, Critical thinking framework, Conclusion), F. Agrusti (Measure language complexity, Results), M.R. Re (Methodology).
} 
ability to evaluate critical thinking skills is essential in facing the urgent need for renewal and innovation, especially in education, and establishing policies aimed at increasing social welfare". Create a connection between distance learning and such kind of skills can strongly contribute to the construction of effective teaching and learning activities, in a lifelong learning prospective.

\section{Research Hypothesis and objectives}

The present research points at investigating, mainly, if:

1. it is possible to create online teaching and learning resources, taking into account the relation process/content in the terms of developing students' critical thinking skills;

2. however, in a situation that is not a face-to-face one, it is possible to establish the integration between online and written message that webcasting allows with easy accessible tools;

3. the use of webcasting supporting traditional teaching and learning improves learning levels of Higher Education students.

The main objectives of the research activities are the following: 1) to define a webcasting learning model thanks to which develop critical thinking skills in university students; 2) to organize and coordinate students' guided discussion on a devoted virtual space; 3) to measure students' critical thinking skills through lexicon-metric analysis and a specific assessment tool which adapt Newman, Webb and Cochrane (1997) model.

\section{Methodology}

About 250 students in Educational Sciences (Department of Education, Roma TRE University) attended, during the academic year 2015/2016, part of the course Methodology of Research through a webcasting activity on Orbis dictus VLE (Vertecchi, et al., 2010. On this platform, six lectures, on some passages taken from Rousseau, Émile ou De l'éducation (1762), were webcast. These lectures were organized by reproducing a model that proved successful at Bologna University in medieval times, and has been replicated in different contexts, including today's (Poce, 2012): 1) distinctio: presentation of the subject; 2) divisio textus: analyses of the constitutive elements of the text; 3) collatio: pros and cons discussion between students and the online tutor; 4) questio: global and critical interpretation of the text. Each passage was presented considering the above phases.

The collatio and the questio phases were carried out through the Forum section on Orbis dictus platform. Each student was asked to present, after the video visualization, her/his comments about the themes and the central elements of the video itself and start a 
discussion under the guide of the online tutor. For each video, an online discussion has been developed and about 250 students have interpreted, presented questions and new ideas, argued, analysed and critically interpreted the six lectures/videos in webcasting format. During the project, an online tutor moderated the discussion. The tutor was responsible for keeping in touch with participants, motivating students in the activities, according to the time schedule, directing the discussion towards the achievement of a specific learning objective, while briefly summarizing the key points that emerged in each discussion. The project has entailed the use of a content analysis model able to measure the critical thinking contribution provided by the students when they were engaged in the production of written text during the collatio and questio activities. The data analyses on the texts produced by the participants were developed to verify if any improvement in students' critical thinking skills occurred and if the use of webcasting really helps Higher Education students learning levels. To conduct such analyses, two research tools were used: 1) a survey to indicate the descriptive data of participants. To promote an individualized approach centred on defined didactic objectives, we created a student profile with the most frequent values, which provided the operative instructions to the research group; 2) lexicon-metric analyses of the written productions of students. All the written materials produced by students were analysed in-depth to measure students' language complexity in relation with the critical thinking framework identified by Newman, Webb and Cochrane's model (1997) and described below in detail. The issue related to the analyses of the text produced online by students has already been discussed on several levels (Poce, 2012; Poce et al., 2015). Marra et al. (2004) carried out an investigation of the analysis models available and identified the one developed by Newman, Webb and Cochrane, as the most comprehensive to evaluate the quality of online interactions, implemented within a discussion forum active for university students. As stated above, in this contribution, such model was adapted and used for the analysis. The following two paragraphs describe the tools in detail and give reasons for the choices employed. 


\section{Critical thinking framework}

As stated above, the current study employed an adapted version of Newman, Webb and Cochrane model to assess critical thinking contribution by the students in the text provided during the collatio and questio activities. Critical thinking skills are fundamental requirements for those who attend a degree course and are requested to use the knowledge acquired to generate new knowledge in a logic structure. If there is absence, or worrying lack of the possession of such skills, interventions are needed. A cultivated critical thinker can be identified (Paul and Elder, 2012; 15) as one who: raises vital questions and problems, formulating the clearly; gathers and assess relevant information and effectively interprets it; comes to well-reasoned conclusions and solutions; think open-mindedly within alternative system of thought, recognizing and assessing; communicates effectively with others in figuring out solutions to complex problems. The researcher used an assessment tool, already tested, which contains the criteria adopted to assign the student's written production to the critical thinking categories. The assessment of the evolution of critical thinking skills was carried out through lexical analysis of the written production by the students. Each text measure has been used to assess one or more categories of the critical thinking skills mentioned above.

Table 1. Critical thinking skills categories

\begin{tabular}{|c|c|c|}
\hline $\begin{array}{l}\text { Category } \\
\text { (Indicator) }\end{array}$ & Definition & Encoding rules \\
\hline Justification & $\begin{array}{l}\text { Argumentation of one's own proposals } \\
\text { and solutions. }\end{array}$ & $\begin{array}{l}\text { Proofs of justifications in favour of the } \\
\text { solutions found or for the opinion } \\
\text { expressed are present (+) or not (-). }\end{array}$ \\
\hline Relevance & $\begin{array}{l}\text { The fundamental issue required by the } \\
\text { question is mentioned. }\end{array}$ & $\begin{array}{l}\text { Relevant }(+) \text { or no relevant }(-) \\
\text { statements or digression. }\end{array}$ \\
\hline Importance & $\begin{array}{l}\text { Knowledge of the topic (important facts } \\
\text { related to the topic are mentioned). }\end{array}$ & $\begin{array}{l}\text { References to important or no } \\
\text { important issues to answer the question } \\
\text { appropriately are present (+) or not (-). }\end{array}$ \\
\hline $\begin{array}{l}\text { Critical } \\
\text { evaluation }\end{array}$ & $\begin{array}{l}\text { Personal and critical elaboration of } \\
\text { sources, background and ideas. }\end{array}$ & $\begin{array}{l}\text { Critical evaluation of the idea proposed } \\
\text { is present }(+) \text { or not (-). }\end{array}$ \\
\hline $\begin{array}{l}\text { Novelty, } \\
\text { new ideas }\end{array}$ & $\begin{array}{l}\text { New information, new ideas and } \\
\text { solutions to the issues raised in the } \\
\text { question are provided. }\end{array}$ & $\begin{array}{l}\text { Further information, new ideas, } \\
\text { possible solutions to the problem are } \\
\text { present }(+) \text { or not (-). }\end{array}$ \\
\hline
\end{tabular}




\section{Measure language complexity}

Language has a powerful effect on human relationships but at the same time it could be considered as an effective tool for manipulation and control. The branch of linguistics known as critical discourse analysis (CDA), or more commonly as critical linguistics, views language as a form of social practice. In the 1970s, just after the first developing of this interdisciplinary approach, it rapidly seemed important to researchers to raise the awareness about the link between ideology and language (Halliday, 1989; Fowler, 1996). Using some of the simplest lexical concepts present in literature, in this section some relevant text measures emphasizing the lexical aspects of language production are presented, in order to identify students' skills through a detailed analysis of their lexical choices. Hereafter some of the most used lexical measures are shown in lexical analysis. Several indexes are presented to compare the different texts collected: 1) lexical density indexes: these indexes measure the proportion of different words classes (in this preliminary research we are using adjectives, verbs and nouns) to the total number of tokens (all the words contained in the text) (Johansson, 2008). Part of Speech (POS) recognition is crucial for computing these indexes and in this research, we used an automatic tool to annotate texts with POS and lemma information called tree-tagger ${ }^{2}$; 2) number and length of sentences: these indexes measure how many sentences are contained into the corpus and the mean length of sentences (in words). Though this value is insensitive to structural differences within sentences, in literature it is recognized as a reliable indicator of grade level ( $\mathrm{Lu}$, et al., 2011); 3) Type-Token Ratio (TTR): this index measures the ratio between how many different words are used (types) in relation with how much these words are repeated into the corpus (tokens). This index is dependent on the text size: it increases as texts contained in the corpus get smaller. Due to this, the comparison is not valid on different-sized texts unless probabilistic models and other statistical approximations are taken into account (Baayen, 2008). Mean Segmental Type-Token Ratio (MSTTR). This index represents the simplest transformation of TTR, calculating the TTR on small segments of original texts and then taking the mean ( $\mathrm{Lu}$, et al., 2011). This index reduces the text size effect above mentioned.

\footnotetext{
2 About tree-tagger software see: http://www.cis.uni-muenchen.de/ schmid/tools/TreeTagger/
} 


\section{Results}

Table 2 shows main results for collected corpora. The type-token ratio did not provide any useful information since it is between .07 to .09 for each corpus. Considering for example Video 1 and Video 3 corpora, the probability of encountering a new type at the end of the first corpus is 9 per cent, while in the second one this is only 2 per cent more likely. From the time that considered corpora were of comparable size, we obtained similar results with MSTTR index.

Table 2. Lexical diversity and density results.

\begin{tabular}{ccccccc}
\hline Variable & Video 1 & Video 2 & Video 3 & Video 4 & Video 5 & Video 6 \\
\hline Tokens & 61211 & 66866 & 60411 & 51955 & 57078 & 65655 \\
Types & 5487 & 5074 & 4105 & 3920 & 4209 & 5252 \\
Lemmas & 3481 & 3197 & 2676 & 2578 & 2803 & 3294 \\
Sentences & 2301 & 2987 & 2504 & 2014 & 2478 & 2879 \\
Avg. sent. len. (in words) & 26.6 & 22.39 & 24.13 & 25.8 & 23.03 & 22.8 \\
TTR & 0.09 & 0.08 & 0.07 & 0.08 & 0.07 & 0.08 \\
MSTTR & 0.79 & 0.76 & 0.76 & 0.77 & 0.78 & 0.77 \\
N ratio (\%) & 26.31 & 26.78 & 25.14 & 25.35 & 25.07 & 25.53 \\
V ratio (\%) & 15.09 & 17.12 & 16.77 & 16.46 & 16.90 & 17.93 \\
Adj ratio (\%) & 9.85 & 9.96 & 10.59 & 10.72 & 10.61 & 9.84 \\
\hline
\end{tabular}

Source: Dataset collected by LPS research team in December 2016.

Lexical density was computed separately for nouns, verbs and adjectives, cumulatively for all texts in each corpus. The proportion of nouns is more than .25 in every corpus. There are fewer verbs in Video 1 corpus (.15) and more than .16 out of all tokens for other corpora. There is no significant difference is for the proportion of adjectives, varying from .09 and .10. These data suggest that there is a large amount of words carrying "nominal" information, whereas Video 6 corpus contains largest proportions of verbs. Since spoken texts tend to have lower lexical density (Halliday, 1989), we could assume that Video 1 texts are closer to spoken language, while other corpora are closer to written language, although the difference is minimal. For what concerns the mean sentence length, there are on average more than 25 words per sentence in Video 1 and Video 4 texts (see table 1), and more than 21 words in an average sentence of other corpora. According to the Flesch's analysis of the readability of adult reading materials (1974), the score for the first two corpora corresponds to style categories "difficult" and the other to "fairly difficult". 


\section{Conclusion}

The aim of this paper was to identify innovative ways to assess higher education students' critical thinking skills in online environments. The idea at the basis of the teaching and learning programme offered to the students was that of starting from meaningful online cultural insights in general and webcasting in particular. On one side, we introduced the assessment grid used for evaluating critical thinking skills level in students' written argumentation; on the other side, we presented a language complexity analysis of these text productions. As expected, the lexical diversity as measured by TTR did not reveal any significant difference in the vocabulary size between corpora. All the corpora displayed a similar amount of information wrapped in nouns, but Video 1 language can be described as the more informal, because its lexical density is lower in general, and this can be due to the nature of the stimuli prompted in the video, which was essentially the presentation of the author of the text, object of the other videos. On the basis of average sentence length, Video 1 and Video 4 corpora can be described as "difficult-style" text productions, appropriate in higher education or adult learners' settings. More analyses are needed to understand connections, if any, between length and density indicators and critical thinking skills levels to be measured according to the adapted Newman Webb Cochrane (1997) model.

\section{References}

Baayen, R. H. (2008). Analyzing linguistic data: A practical introduction to statistics using R. Cambridge University Press.

Flesch, R. (1974). The art of readable writing: with the Flesch readability formula. Harper \& Row.

Fowler, R. (1996). On critical linguistics. In Caldas-Coulthard, R. and M. Coulthard (eds). (1996). Texts and Practices: Readings in Critical Discourse Analysis. London: Routledge.

Giannakos, M. N., \& Vlamos, P. (2013). Using webcasts in education: Evaluation of its effectiveness. British Journal of Educational Technology, 44(3), 432-441.

Halliday, M.A.K. (1989). Spoken and written language. Language education. Oxford Press.

Hargis, J., \& Wilson, D. (2005). Fishing for learning with a podcast net. University of North Florida.

Johansson, V. (2008). Lexical diversity and lexical density in speech and writing. Lund University, Department of Linguistics and Phonetics.

Kurtz, B. L., Fenwick Jr., J. B., \& Ellsworth, C. C. (2007). Using podcasts and tablet PCs in computer science. 45th annual ACMSoutheast regional conference, (pp: 484-489). Winston-Salem, NC, USA.

Lu, X., Thorne, S. L., \& Gamson, D. (2011). Toward a Framework for Computational Assessment of Linguistic Complexity of Grade-level Reading Materials. Ref Type: Unpublished Work. 
Marra, R. M., Moore, J. L., Klimczak, A. K. (2004). Content Analysis of online Discussion Forums: a comparative Analysis of Protocol. Educational Technology Research and Development, 52 (2), 23-40.

Newman D.R., Webb B., Cochrane C. (1997). Evaluating the quality of learning in computer supported cooperative learning. Journal of the American Society for Information science, 48, 6, 484-495.

Oliver, B. (2005). Mobile blogging, 'Skyping' and podcasting: Targeting undergraduates' communication skills in transnational learning contexts [electronic version]. Microlearning, 157-162.

Paul, R. \& Elder, L. (2012). The international critical thinking reading \& writing test: how to assess close reading and substantive writing. Foundation for Critical Thinking.

Poce, A. (edited by) (2012). Contributions to the definition of a critical technology. An assessment study. Milano: FrancoAngeli.

Poce, A., Vertecchi, B., Agrusti, F., Re, M. R. (2015). Pen or keyboard- An empirical study on the effects of technology on writing skills. In Texeira A. et al. eds., EDEN 2016, Reimagining Learning Environments, EDEN, Budapest, ISBN 978-615-5511-08-0.

Traphagan, T., Kucsera, J. V., Kishi, K. (2009). Impact of class lecture webcasting on attendance and learning. Educational Technology Research and Development, 58(1), 19-37.

Trilling \& Fadel (2009). 21st Century Skills: LearningFor Life in Our Times. Jossey-Bass.

Vertecchi, B. (2012). Preface in Poce, A. (edited by) Contributions to the definition of a critical technology. An assessment study. Milano: FrancoAngeli.

Vertecchi, B., Poce, A., Angelini, C., Agrusti, F. (2010). Orbis dictus. Un ambiente adattivo multilingue per l'istruzione in rete. Milano: FrancoAngeli. 